\title{
秎 \\ TRANSPARÊNCIA E INTERESSE PÚBLICO: O TRABALHO DE ACESSO À INFORMAÇÃO E COMUNICAÇÃO PÚBLICA NA CÂMARA MUNICIPAL DE UBERLÂNDIA - MG
}

\author{
TRANSPARENCY AND PUBLIC INTEREST: THE WORK OF ACCESS TO \\ INFORMATION AND PUBLIC COMMUNICATION IN UBERLÂNDIA'S CHAMBER
}

\author{
TRANSPARENCIA E INTERÉS PÚBLICO: LA OBRA DE ACCESO A LA \\ INFORMACIÓN PÚBLICA Y COMUNICACIÓN EN EL AYUNTAMIENTO DE \\ UBERLÂNDIA - MG
}

\author{
Letícia D. Gonçalves Medeiros ${ }^{1}$ \\ Adriana C Omena Santos ${ }^{2}$
}

\begin{abstract}
Resumo: A pesquisa teve como pilares o interesse público e a transparência tendo como objeto de estudo a Câmara Municipal de Uberlândia-MG. Foi realizada a partir do monitoramento das mídias sociais e do site institucional para entender como as pautas legislativas são apresentadas à população. A partir dos resultados pode-se observar como o Poder Legislativo trabalha a questão da Comunicação Pública $(\mathrm{CP}) \mathrm{e}$ a se os preceitos da Lei de Acesso à Informação (LAI) são respeitados. Metodologicamente foram utilizados levantamento bibliográfico e documental seguidos de análise de conteúdo das publicações de Facebook e Instagram à luz dos conceitos estudados. Os resultados apontam que o interesse público e a transparência não são efetivamente trabalhados pela instituição nas mídias sociais e que no site o acesso à informação se mostra comprometido, tanto no que diz respeito à transparência ativa quanto passiva.
\end{abstract}

Palavra-chave: Comunicação pública; Lei de Acesso à Informação; Câmara de Uberlândia.

Abstract: The research had as pillars the public interest and transparency having as object of study the Municipality of Uberlândia-MG. It was carried out through the monitoring of social media and the institutional website to understand how the legislative guidelines are presented to the population. From the results, it can be seen how the Legislative Branch works on the issue of Public Communication (CP) and whether the precepts of the Access to Information Law (LAI) are respected. Methodologically, bibliographical and documentary surveys were used, followed by content analysis of Facebook and Instagram publications in the light of the concepts studied. The results show that the public interest and transparency are not effectively addressed by the institution on social media and that access to information on the website is compromised, both with regard to active and passive transparency.

Keywords: Public Communication; Access to Information Law; Uberlândia's Chamber.

Resumen: La investigación tuvo como pilares el interés público y la transparencia teniendo como objeto de estudio el Municipio de Uberlândia-MG. Se llevó a cabo p del seguimiento por el seguimiento de las redes sociales y el sitio web institucional para comprender cómo se presentan los lineamientos legislativos

\footnotetext{
${ }^{1}$ Jornalista e Mestre em Tecnologias Comunicação e Educação pela Universidade Federal de Uberlândia (UFU). ORCID https://orcid.org/0000-0003-0768-0750. E-mail. leticiadaniela@live.com

2 Publicitária pela Universidade Metodista de Piracicaba (Unimep), Mestre e Doutora em Ciências da Comunicação pela Universidade de São Paulo (USP), com Pós-doutorado em Comunicação da Ciência pela Universidade de Ottawa (UOttawa). Professora no curso de Jornalismo, no Programa de Pós-graduação em Tecnologias, Comunicação e Educação (mestrado profissional) e no Programa de Pós-graduação em Educação (mestrado e doutorado), todos na Universidade Federal de Uberlândia (UFU). ORCID https://orcid.org/0000-0002-8863-6219. E-mail adriomena@gmail.com
} 
a la población. De los resultados se desprende cómo trabaja el Poder Legislativo en el tema de Comunicación Pública (PC) y si se respetan los preceptos de la Ley de Acceso a la Información (LAI). Metodológicamente, se utilizaron encuestas bibliográficas y documentales, seguidas del análisis de contenido de las publicaciones de Facebook e Instagram a la luz de los conceptos estudiados. Los resultados muestran que el interés público y la transparencia no son abordados de manera efectiva por la institución en las redes sociales y que el acceso a la información en el sitio web se ve comprometido, tanto en lo que respecta a la transparencia activa como pasiva.

Palabras clave: Comunicación publica; Ley de Acceso a la Información; Cámara de Uberlândia.

\section{Introdução}

O artigo traz resultados da pesquisa que teve como tema a comunicação pública, mais especificamente na área da política, tendo como objeto a Câmara Municipal de Uberlândia-MG e partiu de inquietações a respeito da prática exercida pela assessoria de comunicação no órgão legislativo de uma das maiores cidades de Minas Gerais, bem como entender as formas que são utilizadas para o acesso à informação. O departamento de comunicação em questão, de acordo com o site institucional, é formado por um diretor geral e tem duas subdivisões, sendo elas a seção de jornalismo e a de cerimonial.

Assim, o estudo acompanhou e analisou as mídias sociais por três meses, entre abril e junho de 2020, e o site da citada instituição, observando como são tratadas e divulgadas as questões de interesse público, sejam as matérias legislativas ou informações exigidas pela Lei de Acesso à Informação. O período acima citado foi escolhido por conta do início da pandemia de Covid-19 no país e para entender como a instituição lidaria com o acesso e divulgação de informações justamente quando a população mais precisava delas, especialmente online, já que o isolamento social impossibilitou o acompanhamento presencial de sessões e a internet tornou-se essencial para acompanhar os processos.

Levando em consideração que as matérias discutidas no Poder Legislativo são de interesse público e a maioria delas não chega efetivamente ao seu público de interesse, seja pelos meios de divulgação ou pela linguagem não acessível, a questão norteadora da pesquisa buscou responder como a Câmara Municipal de Uberlândia trabalha a comunicação pública nas mídias sociais e em seu site. Para tanto, foram aprofundados os conceitos acerca de comunicação pública e lei de acesso à informação para, posteriormente, estudar se o órgão atende aos critérios exigidos pelos conceitos e pela legislação. Além disso, houve uma observação das páginas oficiais do Facebook e Instagram e do site institucional com a finalidade de averiguar como são tratadas e divulgadas as questões de interesse público nos canais oficiais de comunicação, bem como ponderar os conteúdos das matérias legislativas, mensuração da resposta dos usuários às postagens nas mídias, sempre enfatizando as ações que trabalhem a comunicação de interesse público, observando também a linguagem empregada e a mídia. 
Transparência e interesse público: o trabalho de acesso à informação e comunicação pública na Câmara Municipal de Uberlândia -MG

\section{A cidade e a Câmara Municipal de Uberlândia-MG}

Uberlândia é um município de Minas Gerais, localizado na região do Triângulo Mineiro. Dados do Instituto Brasileiro de Geografia e Estatística (IBGE) mostram que, em 2020, a cidade tinha uma população estimada de 699.097 habitantes, o que coloca o município como o segundo maior em população do estado de Minas Gerais.

De acordo com o site oficial, o Índice de Desenvolvimento Humano (IDH) de Uberlândia em 2010, foi de 0,789, o que é considerado alto pela Organização das Nações Unidas (ONU), sendo o terceiro mais alto de Minas Gerais e o $71^{\circ} \mathrm{em}$ um ranking nacional. Uberlândia é frequentemente citada em pesquisas que consideram a qualidade de vida e desenvolvimento urbano: a primeira cidade de Minas Gerais e terceira do país em saneamento básico, em 2019, de acordo com o Trata Brasil; ocupa a posição 57 entre as cidades mais inteligentes e conectadas do país, em 2019, de acordo com o Connected Smart Cities; é a 46 melhor cidade do país para se fazer negócios, em 2019, pela Urban Systems; é a 23ª melhor cidade do Brasil, em 2018, de acordo com o Índice dos Desafios da Gestão Municipal.

O Poder Legislativo de Uberlândia, em seu site institucional, apresenta um breve histórico da Câmara Municipal e do início da atuação política na cidade. Segundo a página, até o ano de 2020, quando ainda vigoram os representantes eleitos em 2016, a CMU possuía 27 vereadores: Adriano Zago, Amado Júnior, Antônio Borges (Tunico), Antônio Carrijo, Átila Carvalho, Charlie Manzi (Charlão), Cleyton César, Delfino Rodrigues, Edilson Gracioli, Ednaldo Régio, Eduardo Moraes, Gláucia Galante, Guilherme Fernandes, Heliomar Cândido (Bozó), Jussara Matsuda, Leandro Neves, Liza Prado, Marcelo Cunha, Mineia Nunes, Misac Lacerda, Neivaldo Honório (Magoo), Paulo César (PC), Ronaldo Tannus, Sergimar Melo (Sérgio do Bom Preço), Thiago Fernandes, Walquir Amaral e Wilson Pinheiro, que representam 12 partidos políticos diferentes (MDB, PCdoB, PDT, PL, PMB, PP, PSC, PSD, PSDB, PSL, PT e SD). É a essa legislatura, portanto, que se refere o material coletado e analisado ${ }^{3}$.

A Mesa Diretora da CMU é a responsável por dirigir os trabalhos legislativos nas reuniões ordinárias e extraordinárias, bem como cuidar dos serviços administrativos da Câmara pelo período de dois anos. Atualmente, a estrutura é composta por Presidente, Primeiro, Segundo e Terceiro Vice-Presidentes e Primeiro e Segundo Secretários. Já as Comissões de Trabalho, que elaboram os pareceres dos projetos juntamente com a assessoria técnica, são 17: Comissão de Administração Pública; Comissão Mista de Participação Popular Legislativa; de Direitos Humanos Sociais e do Consumidor; de Educação, Cultura e Ciência; de Esporte, Lazer e Paradesporto; de Finanças, Orçamento e Tributos; de Indústria, Comércio, Turismo e Trabalho; de Inovação, Tecnologia e Juventude; de Legislação, Justiça e Redação; de Meio Ambiente e

\footnotetext{
${ }^{3}$ Parte dos nomes citados aqui são de vereadores suplentes que assumiram o mandato em 2020 depois da operação Má Impressão, do Grupo de Atuação Especial de Combate ao Crime Organizado (Gaeco), em dezembro de 2019. Ao todo 20 vereadores foram presos e perderam o mandato em ações de cassação posteriormente.
} 
Defesa Animal; de Micro e Pequena Empresa; de Política Rural e Administração dos Distritos; de Política Urbana, Habitação e Urbanismo e Transporte Público; de Políticas Públicas sobre Drogas; de Promoção da Igualdade Racial; de Saúde e Saneamento Básico; e Comissão de Segurança Pública.

Conforme o organograma disponível no site institucional, o setor de Comunicação da CMU está alocado na Secretaria-Geral e divide-se em na TV Legislativa (Seção de produção gráfica e fotográfica e Seção de Áudio e Vídeo) e no Departamento de Comunicação (Seção de Cerimonial e Seção de Jornalismo). Este último é o setor responsável pela assessoria de imprensa, textos e todo material coletado e analisado neste trabalho. De acordo com o Portal da Transparência, no mês de novembro de 2020, havia 4 servidores no setor de jornalismo, 1 no setor de cerimonial e 1 diretor de comunicação. Três desses servidores são jornalistas, cuja função exige formação superior em Jornalismo e registro profissional na área.

\section{Comunicação, interesse público e acesso à informação}

Comunicação Pública e assessoria de imprensa.

A discussão sobre comunicação pública $(\mathrm{CP})$ é recente e vem crescendo em todo o mundo. No caso do Brasil, o conceito surgiu em meados de 1980 e Koçouski (2012) aponta que o início das discussões acerca do tema está diretamente ligado a dois favores: a redemocratização do país e a criação da Constituição Federal de 1988. Nesta última, a autora destaca que os tópicos da legislação que tratam das liberdades de imprensa e de expressão, bem como a exigência da transparência nos atos do governo, fortaleceram a CP no país. Talvez por esse início o termo esteja ligado à comunicação governamental. No entanto, os principais estudiosos do termo apontam ser um erro simplificar a CP apenas a isso.

Como afirmam Ribeiro e Mainieri (2011), a definição de comunicação pública é polissêmica e seu estudo ainda tem muitos caminhos a serem percorridos. $\mathrm{O}$ conceito ainda busca consolidação e segue acompanhando "de modo incipiente as mudanças na institucionalidade democrática e as demandas por participação e democratização no processo decisório das políticas públicas" (SARDINHA, 2012, p. 2).

Outros teóricos concordam ao dizer que "a comunicação pública configura um conceito complexo que permite extrair múltiplas abordagens teóricas e reflexões sobre sua prática nas diferentes perspectivas do campo comunicacional" (KUNSCH, 2013, p. 17). Para Brandão (2006), o termo comunicação pública vem sendo utilizado com diversos significados, dependendo do país e do autor. Para a autora, trata-se de um campo novo e que se encontra ainda em construção e como forma de contribuir para a conceituação teórica é possível identificar cinco áreas diferentes de conhecimento e atividade profissional: CP com comunicação organizacional, com comunicação científica, com comunicação estatal/governamental, com comunicação política e 
com estratégias de comunicação da sociedade civil organizada.

A CP desempenha papel fundamental em todo o processo de controle social que deve ser exercido pela sociedade. Sendo assim, pode-se considerar que a "Comunicação Pública deve ser pensada como um processo político de integração no qual prevalecem a expressão, a interpretação e o diálogo" (MATOS, 2011 apud KUNSCH, 2013, p.6). Em sua essência, a CP deve ser não apenas participativa, mas também inclusiva, garantindo que as vontades coletivas se sobreponham às individuais, em uma comunicação democrática.

Cabe recorrer, neste contexto, a Duarte, um dos nomes que estuda a CP. De acordo tal autor, os objetivos da Comunicação Pública são:

[...] privilegiar o interesse público; centralizar o processo no cidadão; tratar a comunicação como um processo dialógico; adaptar instrumentos às necessidades, possibilidades e interesses públicos; e, assumir a complexidade da comunicação, tratando-a como um todo. No serviço público, a comunicação assume um papel importante para a democratização da informação, principalmente, nas prefeituras. (DUARTE, 2009, p. 59).

Não diferente disso, é possível citar que a $\mathrm{CP}$ e as instituições públicas possuem finalidades semelhantes, principalmente quando dizem respeito às funções de informar; escutar; contribuir para assegurar a relação social e acompanhar as mudanças de comportamento e das organizações sociais (ZÉMOR, 2005 apud BRANDÃO, 2006, p. 13). O autor aponta, ainda, que a CP é comunicação de interesse público.

Pode-se concluir brevemente que a intenção da comunicação pública é transmitir aos cidadãos informações que são de interesse público, estabelecendo a transparência e a possibilidade de diálogo entre o Estado e a sociedade. Tendo como objeto de estudo a Câmara Municipal de Uberlândia, mas considerando qualquer unidade do Poder Legislativo, as informações que tais órgãos possuem (e que são de interesse público) dizem respeito, primordialmente, às discussões e criações de legislações que podem estabelecer direitos e deveres para os cidadãos. Uma vez sendo o poder responsável pela criação das leis, as câmaras configuram um espaço que deveria permitir a discussão pública e o atendimento às necessidades de uma população já no primeiro passo da criação das leis. Ouvir a população durante o processo é uma forma de garantir o exercício da democracia em sua forma mais básica.

Como a proposta desta pesquisa trata de analisar materiais do Poder Legislativo de Uberlândia, cabe recorrer a Haswani (2013) quando a autora trabalha o discurso obscuro das leis. Sendo a Câmara Municipal a responsável pela aprovação das leis de interesse da comunidade, precisamos considerar que a linguagem jurídica, usada nessas legislações, não é clara e acessível a todos. O que se fala aqui corresponde a

[...] uma comunicação usada sobretudo dentro do modelo tradicional de administração, chamado de regulação. Os exemplos vão das certificações, verbalizações e notificações às publicações legais, as coletâneas oficiais de 
atos, os afixos nos murais, os depósitos permanentes de documentos com exposição ao público, os registros e similares (ARENA, 1999 apud HASWANI, 2013, p. 33).

Sendo assim, outra forma de utilizar a CP seria buscar formas de ultrapassar estes obstáculos, disponibilizando as informações de forma que garanta a comunicação efetiva entre a instituição e a sociedade. Haswani (2013) acrescenta ainda que a comunicação das leis é obrigatória, mas a forma como é realizada recebe críticas de estudiosos. Eles acreditam que a linguagem e os meios utilizados para divulgar não são adequados à finalidade. A pesquisadora acrescenta, também, que o uso de terminologia técnica resulta na incompreensão por parte da maioria do público. Por consequência, esta obscuridade acaba por prejudicar não apenas a aplicabilidade das leis, mas também ambiguidade, incoerência e irracionalidade (AINIS, 1997 apud HASWANI, 2013). Dessa forma, "sem conhecimento das leis não há como cobrar ao cidadão o seu cumprimento e, do outro lado, não há como reivindicar ao Estado a realização dos direitos fundamentais e sociais a que fazem jus" (HASWANI, 2013, p.34).

Explicados alguns dos conceitos fundamentais da comunicação pública, é importante abordar o conceito da assessoria de imprensa, desde sua criação até as funções dos profissionais desta área. Tratar da CP e da assessoria de imprensa ao falar sobre interesse público tem como objetivo mostrar como os órgãos públicos, como no caso desta pesquisa, podem aplicar a comunicação de interesse da população dentro das instituições e levar tais informações aos mais interessados, que são os cidadãos. Para tanto, os profissionais da assessoria de imprensa tornamse fundamentais, uma vez que são eles os responsáveis pelo setor de comunicação desses órgãos.

Nas instituições públicas, o assessor de imprensa tem como foco priorizar o:

[...] interesse público, o que exige uma prestação de contas, que é uma obrigação legal, do que é realizado pela organização. Neste caso, isso exige da assessoria de imprensa um trabalho que, além de dar visibilidade às organizações, tenha como finalidade a veiculação de informações da gestão pública que tenham impacto direto na sociedade (FLORES, 2016, p.37).

Diferente do que se pensa, lidar com assessoria de imprensa no setor público não está ligado a promover os governantes, mas prezar pela prestação de contas, transparência e uma comunicação efetiva que procure atender ao interesse da população. Assim, prestar contas e ser transparente nas ações não está dissociado do interesse público. Pelo contrário: agir de acordo com tais preceitos é não apenas uma obrigação prevista por lei, mas também - e aqui pensando em outra vertente da assessoria de comunicação - uma forma de tratar a imagem das instituições. A transparência pode agregar uma imagem positiva ao órgão, trazendo mais confiabilidade perante o público. Assim, se considerada e feita dessa forma, os profissionais da assessoria de imprensa são os responsáveis por cuidar da comunicação pública nesses órgãos, levando o direito à informação aos cidadãos.

Apesar de as assessorias de imprensa serem ocupadas muitas vezes por jornalistas, a 
Transparência e interesse público: o trabalho de acesso à informação e comunicação pública na Câmara Municipal de Uberlândia -MG

relação destes com os assessores de imprensa, por vezes profissionais de relações públicas, nem sempre se dá de forma harmônica, mesmo que ambos os profissionais sejam da mesma área de conhecimento (e entendam o trabalho um do outro). É comum existir um conflito entre os dois profissionais devido ao fato de que os assessores detêm as informações e nem sempre facilitam o acesso delas aos jornalistas que trabalham nos meios de comunicação. Ao discorrer sobre o assunto Dines (2009) apresenta três relações entre estes profissionais: a) Assessoria E Imprensa; b) Assessoria OU Imprensa; e c) Assessoria VERSUS Imprensa, sendo tais relações otimista, pessimista e dramática, respectivamente.

No primeiro caso, o autor considera um espaço de colaboração no qual só a assessoria possui determinadas informações e as fornece aos jornalistas, estabelecendo uma relação em que todos saem ganhando: os dois trabalhos são respeitados, o meio de comunicação ganha uma informação e materiais importantes para divulgação e a instituição ganha visibilidade na mídia. Já o segundo caso diz respeito às assessorias que usam a imprensa para evitar que determinados assuntos sejam publicados, explorando infiltrações ou deficiências de recursos dos meios.

A partir tanto dos autores consultados, quanto da prática profissional observada, é possível afirmar que a relação deve ser harmônica como na primeira abordagem apresentada pelo autor, uma vez que é possível estabelecer uma relação em que ambos sejam beneficiados no processo. Entretanto, em uma visão realista, é impossível ignorar que as outras duas situações existem e que são recorrentes no meio. É preciso refletir, portanto, sobre o papel social do assessor de imprensa e como ele pode atentar tanto para cuidar da imagem da instituição quanto para respeitar o dever de ser transparente nos atos públicos (que já são obrigações previstas na LAI).

Um ponto de vista que não deve ser ignorado é que a instituição (ou agente público) que agir impedindo o trabalho de divulgação da imprensa, ou até mesmo escondendo dados para manter uma "boa imagem" do órgão, torna-se suscetível a uma série de problemas, incluindo a perda de credibilidade perante os cidadãos interessados pelo assunto, com a imprensa e, também, com os próprios meios de comunicação. Para a assessoria de comunicação/imprensa, manter jornalistas e a mídia como "aliados" pode ser útil principalmente em crises e casos em que a boa imagem da instituição é colocada em xeque, uma vez que os assessores serão procurados e, assim, as questões podem ser resolvidas com mais facilidade.

Uma vez tomado como objeto de pesquisa a Câmara Municipal de Uberlândia, torna-se necessário fazer uma análise no que tange o exercício da assessoria de imprensa na administração pública. Citando a visão de Moreira e Ulhôa (1996), Tavares (2016) relata que o assessor de imprensa, por vezes, tem uma visão tecnicista de todo o processo de comunicação desta organização. Entre algumas das percepções do profissional, a autora cita que ele pode "interferir nos planos de governo, nas promoções e até nos orçamentos, além de gerar fatos. Ele estabelece um filtro inicial da divulgação, porque ele tem conhecimento técnico sobre o que pode e o que não pode ser notícia” (TAVARES, 2016, p. 43). 
Nesse contexto é possível analisar como a assessoria de imprensa pode operar a comunicação pública e inovar utilizando as funcionalidades tecnológicas disponíveis. A necessidade de mudança vem, principalmente, da evolução constante dos meios de comunicação e da velocidade em que as informações circulam. Colaborando com esta ideia de transformação constante, Brandão (2006) aborda que a mudança política também trouxe alterações no modo de comunicar alternativo até o conhecimento da população sobre os direitos de acesso à informação, transparência e prestação de contas à sociedade.

\section{Lei de Acesso à Informação (LAI) e Accountability}

No Brasil, o acesso à informação pública está inscrito no capítulo I da Constituição Federal, espaço em que se trata dos Direitos e Deveres Individuais e Coletivos, no inciso XXXIII do artigo 5. Sobre o assunto, diz que "todos têm direito a receber dos órgãos públicos informações de seu interesse particular, ou de interesse coletivo ou geral, que serão prestadas no prazo da lei, sob pena de responsabilidade, ressalvadas aquelas cujo sigilo seja imprescindível à segurança da sociedade e do Estado" (BRASIL, 1988, art. 5º.

Além disso, o acesso à informação é previsto legalmente desde o ano de 2012, por meio do Decreto $\mathrm{n}^{\circ} 7.724$, de 16 de maio, regulamentando a Lei $\mathrm{n}^{\circ} 12.527$, de 18 de novembro de 2011 - resultado de debates em órgão vinculado à Controladoria Geral da União. Em seu texto, a legislação regula os processos que assegurem o acesso e a classificação de informações sob restrição de acesso, observados grau e prazo de sigilo. Assim, os órgãos e entidades garantem "às pessoas naturais e jurídicas, o direito de acesso à informação, que será proporcionado mediante procedimentos objetivos e ágeis, de forma transparente, clara e em linguagem de fácil compreensão, observados os princípios da administração pública e as diretrizes previstas na Lei $n^{\circ}$ 12.527, de 2011" (BRASIL, 2012). Uma vez criada para facilitar o acesso às informações e incentivar a participação ativa, a legislação estabelece que as solicitações podem ser feitas mediante preenchimento de formulário, sendo o requerente desobrigado a especificar os motivos do pedido de acesso à informação.

As respostas dadas aos cidadãos que puderem ser feitas por meio eletrônico são gratuitas, mas nos casos em que o fornecimento ocasione reprodução física de documentos, o órgão, de acordo com o artigo 18 da mesma lei, “disponibilizará ao requerente Guia de Recolhimento da União (GRU) ou documento equivalente, para pagamento dos custos dos serviços e dos materiais utilizados" (BRASIL, 2012). Esta reprodução, por sua vez, respeitará o prazo de dez dias a partir do momento em que o solicitante comprovar o pagamento da guia. Em casos de grande volume de material, o prazo pode ser superior, desde que justificado. A LAI estabelece, também, que se o solicitante não tiver condições financeiras de efetuar o pagamento da GRU, é necessário elaborar uma "declaração de pobreza", conforme termos Lei nº 7.115, de 1983.

A LAI propõe, também, regras para o grau de classificação de documentos, sendo eles: 
Ultrassecretos, cujo prazo de segredo é de 25 anos (renovável uma única vez); Secretos, com prazo de segredo de 15 anos; e Reservados, que possuem prazo de segredo de 5 anos. Pela lei, as informações consideradas como ultrassecretas são de competência do Presidente da República, Vice-Presidente da República, Ministros de Estado e autoridades com funções equivalentes, Comandantes da Marinha, do Exército, da Aeronáutica e Chefes de Missões Diplomáticas e Consulares permanentes no exterior (BRASIL, 2012). Além disso, como aponto o artigo 29 da lei, informações que comprometem a segurança do "Presidente da República, Vice-Presidente e seus cônjuges e filhos serão classificadas no grau reservado e ficarão sob sigilo até o término do mandato em exercício ou do último mandato, em caso de reeleição". (BRASIL, 2012).

Além destes aspectos apresentados até o momento, a LAI trata de um ponto importante, que diz respeito ao monitoramento da aplicação da lei. A autoridade máxima de cada órgão irá designar um responsável que deverá garantir que o acesso à informação seja garantido. Esta pessoa poderá, ainda, por fazer recomendações com vistas a melhorar os procedimentos do Decreto que coloca a Lei de Acesso à Informação em vigor.

O site do Governo Federal ${ }^{4}$ tem esta e outras leis disponíveis para consulta. A LAI, em específico, tem um portal que, para além das solicitações, apresenta infográficos que facilitam ao cidadão compreender a legislação em diversos aspectos: a abrangência e os objetivos da lei, como fazer os pedidos, os prazos e, também, relatórios estatísticos da Lei de Acesso. Neste endereço é enfatizado que a solicitação das informações pode ser feita no âmbito dos três Poderes (Judiciário, Legislativo e Executivo) e em todas as esferas de governo (municipais, estaduais, distrital e federal). Os cidadãos são informados, ainda, que os pedidos não exigem motivação e o fornecimento destas informações é gratuito, salvo casos em que haja reprodução de materiais.

Sobre estes pedidos de informação, o Governo Federal explicita que não se encaixam como solicitações dispostos na LAI: desabafos, sugestões ou elogios (estes devem ser direcionados à Ouvidoria do órgão), consultas sobre a aplicação da legislação (que também devem ser encaminhados ao canal adequado - embora não seja citado qual é este canal) e denúncias (estas, quando se referirem ao Poder Executivo Federal, devem ser encaminhadas ao site da CGU; descumprimentos da lei em outras esferas deverão ser encaminhadas para os respectivos órgãos responsáveis).

No serviço público, Amorim e Silva (2014) apresentam um panorama sobre as dificuldades de aplicação da lei, principalmente quando se refere às organizações públicas. Alguns desses obstáculos podem ser vistos no apego às rotinas administrativas, excessiva hierarquia, além da burocracia nos processos internos, apesar de ser uma lei que já vigora há quase oito anos. Esse processo de adequação passa, então, a ser cultural e deve ser trabalhado em todos os níveis dos poderes.

\footnotetext{
${ }^{4}$ Informações https://www.gov.br/acessoainformacao/pt-br.
} 
No âmbito municipal, Batista (2017) defende que, para aplicação da lei, é necessário haver formulação de uma nova política. Mesmo que essa inovação aconteça existem limitações e dificuldades que impedem as ações e um dos fatores impeditivos mais enfatizados na pesquisa é a disponibilidade dos recursos financeiros.

Mais recentemente, Valdiones et al. (2019) publicaram relatórios que analisam os avanços e desafios quando o assunto é transparência e os SICs depois de sete anos que a LAI vigora no país. Os autores apontam que, mesmo vigente há sete anos (até a época da publicação do artigo), os estados apresentam uma série de melhorias que precisam realizar.

O melhor resultado foi a nível Federal, que é feito pela CGU, mas que mesmo assim não atende à totalidade dos critérios, alcançando 93\% de pontuação. No ranking, Alagoas e Maranhão seguem empatados em segundo lugar, com $80 \%$. O estado de Minas Gerais, ao qual a cidade de Uberlândia pertence, cumpre $67 \%$ dos critérios, resultado que representa um número mediano na região sudeste do país.

Pode-se notar, portanto, que a LAI segue como um processo ainda em construção no país, com pontos a serem melhorados em todo o território nacional, inclusive na esfera federal e está diretamente relacionado com o conceito de prestação de contas, algo bastante próximo do termo accountability.

\subsection{Accountability}

Durante a pesquisa foi possível notar que tratar de comunicação e gestão pública leva, frequentemente, à discussão acerca de accountability, um termo inglês vindo da administração que, ainda hoje, não possui uma tradução no Brasil. Ao fazer o levantamento bibliográfico sobre o assunto, é possível encontrar um artigo em que Campos (1990) propõe maneiras de traduzir o termo para a língua portuguesa. Em seu trabalho, ela aponta que a primeira leitura sobre o termo foi de Mosher (1968), que aponta a accountability como:

[...] sinônimo de responsabilidade objetiva ou obrigação de responder por algo. Enquanto a responsabilidade subjetiva vem de dentro da pessoa, a accountability, sendo uma responsabilidade objetiva, "acarreta a responsabilidade de uma pessoa ou organização perante uma outra pessoa, fora de si mesma, por alguma coisa ou por algum tipo de desempenho". E esse autor continua: "Quem falha no cumprimento de diretrizes legítimas é considerado irresponsável e está sujeito a penalidades. (MOSHER, 1968 apud CAMPOS, 1990, p. 33).

O texto de Campos já tem 30 anos de publicação e um trecho chama a atenção, principalmente se associado ao tópico anterior sobre a LAI, que ainda não havia sido criada. Amparada por autores que defendiam o pleno exercício da democracia, a autora já demonstrava preocupação a respeito de quem detinha as informações no serviço público e que o abuso de poder não afetasse o cidadão. Assim, Campos (1990) aponta que a falta de controle e de punições no serviço público poderia afetar o ideal democrático - e a accountability entraria justamente para 
ajudar nesse controle. Dessa forma,

[...] os melhores mecanismos de controle burocrático - incluindo sistemas de recompensas e punições; as práticas de avaliação do desempenho; a estrita definição de autoridade e de responsabilidades - estarão sempre limitados aos valores burocráticos tradicionais: eficiência, honestidade, observância das regras. (CAMPOS, 1990, p.34).

Portanto, o que Campos (1990) observa, no contexto da accountability, são os preceitos tradicionais do sistema burocrático, tais como a eficiência, honestidade e observância das regras. Contudo, ela questiona se apenas esses mecanismos conseguirão garantir que não haja abuso de poder, mas que exista a promoção da justiça social e que o governo trabalhe para o povo. A conclusão é que todos esses pontos só serão assegurados se o cidadão estiver ciente de seus direitos e deveres e praticar a fiscalização.

Trinta anos se passaram desde a publicação da autora e o cenário está diferente do que foi apresentado no texto dela. Quando aponta que o Brasil não segue outras democracias mundiais e, em alguns pontos do texto, defende países como os Estados Unidos, colocando-os em um patamar superior, percebe-se um equívoco da autora ao comparar países com situações diferentes e especificidades em que não se permitem comparações. Cada um deles tem particularidades que devem ser consideradas, como sistema de governo, fatores econômicos e sociais, e diversas outras questões. Considerar a teoria dos mundos e comparar um país desenvolvido ${ }^{5}$ com outro em desenvolvimento ou subdesenvolvido é desconsiderar as desigualdades e estabelecer parâmetros que podem, inclusive, ser inatingíveis.

Com uma abordagem mais recente, Rocha (2011) também aponta as responsabilidades que do sistema democrático tanto para os cidadãos, que tem que saber escolher seus governantes, como estes últimos que precisam prestar contas àqueles que os escolheram para governar. Nesse caso, como o autor já considera a sociedade já formada para defender seus direitos, ele apresenta novos problemas no regime democrático moderno ligado a "desenvolver formas e instrumentos de accountability, isto é, processos de avaliação e responsabilização permanente dos agentes públicos que permitam ao cidadão controlar o exercício do poder concedido aos seus representantes" (ROCHA, 2011, p.84). Ou seja, o governo precisa usar do princípio da publicidade ${ }^{6}$ para mostrar o que ele faz, como faz e disponibilizar canais para que o cidadão entre em contato para solicitar outras informações que não estão disponíveis. Estes canais, por sua vez, podem ser considerados uma forma de suprir as deficiências da administração pública, que não tornam públicos todos os atos do governo, fazendo com que o cidadão pratique a transparência

\footnotetext{
${ }^{5}$ A Teoria dos Mundos usada durante a Guerra Fria para fazer a separação entre países aliados e seu poder econômico. Entre os medidores para classificar um país como de primeiro, segundo e terceiro mundo estão economia, avanço tecnológico, índices sociais, qualidade de vida, entre outros.

6 Os cinco princípios fundamentais da Administração Pública são: Legalidade, Impessoalidade, Moralidade, Publicidade e Eficiência (BRASIL, 1988).
} 
passiva.

Quando se trata da accountability na transparência governamental eletrônica, Cunha et al. (2016) apontam que, com o passar dos anos, as Tecnologias da Comunicação e Informação (TICs) foram potencializadoras do processo, tanto a nível nacional como internacional. Como forma de aproximar o Estado e o cidadão, o uso destas tecnologias "visa melhorar a prestação de contas públicas, permite que terceiros acessem e fiscalizem as ações do governo. A melhor informação, por sua vez, capacita os cidadãos e, portanto, leva a governos mais democráticos e mais confiáveis" (CUNHA et al., 2016, p. 128).

Abordando visões positivas e negativas, Cunha et al. (2016) afirmam que associar transparência à accountability está diretamente ligada à "[...] disponibilizar para a sociedade acesso às instituições de controle (accountability) para que o ciclo entre ambos se complete e, de fato, promova avanços substantivos da democracia ao possibilitar aos governados cobrar responsabilidade de seus governantes" (CUNHA et al., 2016, p. 132).

Posto isso, o tópico seguinte se baseia no que foi conceituado para mostrar como foi o processo de análise e os resultados encontrados nesta pesquisa.

\section{Procedimentos metodológicos}

Levando em consideração a questão sobre como a assessoria de imprensa da Câmara Municipal de Uberlândia trabalha a comunicação pública e para a realização da proposta em questão, bem como atingir os objetivos estipulados, foi realizada uma pesquisa aplicada, descritiva, documental e de natureza qualitativa que, por meio da seleção e análise de documentos, atribui interpretação e significado ao que foi analisado.

Primeiramente, houve um aprofundamento bibliográfico acerca dos principais pontos explorados na pesquisa, tais como os principais autores e conceitos de comunicação pública, accountability, a lei de acesso à informação, além de estudos de temas que contemplem política, cidadania e comunicação no âmbito legislativo. Dessa forma foi possível ter um aparato teórico para sustentar teoricamente os temas trabalhados.

Foi realizado um monitoramento das páginas oficiais do Facebook e Instagram, além de análise do site institucional do objeto da pesquisa. É importante acrescentar que analisar as duas redes trouxe resultados diferentes, porque apesar de cada vez mais unificadas e com funcionalidades semelhantes (mas não idênticas) cada rede tem sua particularidade e foi criada com um intuito. A escolha destas duas mídias sociais deu-se, também, por serem umas das mais utilizadas em todo o mundo. No Brasil, por exemplo, o relatório Digital in 20207 (WE ARE SOCIAL, 2020), feito pela We Are Social em parceria com a Hootsuite, mostrou que há 150,4

\footnotetext{
${ }^{7}$ Hootsuite e We are social são duas agências de marketing digital especializadas em mídias sociais que atuam no mundo inteiro. Elas realizam anualmente pesquisas acerca do mundo da comunicação digital.
} 
milhões de usuários de internet no Brasil e, dentre eles, 140 milhões usam mídias sociais - um aumento de 8,2\% comparado ao ano anterior. O tempo médio diário destes usuários na internet é de 9 h17, das quais $3 \mathrm{~h} 31$ são usados para navegar em mídias sociais. A pesquisa mostrou ainda que o Youtube (96\%), Facebook (90\%), WhatsApp (88\%) e Instagram (79\%) lideram o ranking de preferência dos brasileiros que utilizam as redes.

A coleta dos dados ocorreu por meio de monitoramento entre os meses de abril e junho de 2020 da página oficial do Facebook da Câmara Municipal de Uberlândia com o auxílio da Fanpage Karma, que é uma ferramenta para monitoramento e análise de mídias sociais. Por meio dela é possível ter informações sobre o engajamento, seguidores, análise individual de postagens, melhores dias e horários para publicação, entre outros dados.

Foram coletadas postagens com o intuito de elencar quais os tipos de informações divulgadas na mídia social escolhida. Na página do Instagram foi usada a ferramenta Hype Auditor, que verifica informações sobre o público, engajamento e perfil e interesse dos seguidores. Houve, ainda, uma análise manual, para a análise de sentimentos e da interatividade. Além disso, foi possível notar que o conteúdo das duas mídias sociais citadas é parcialmente replicado: nas postagens coletadas, as fotos e textos do feed são os mesmos, salvo raras exceções nas quais para o conteúdo do Instagram é usado apenas o primeiro parágrafo do texto do Facebook. Assim, como se trata dos mesmos conteúdos, foi feita uma comparação dos resultados apresentados nas duas mídias. Em uma grande escala, os objetivos da pesquisa foram os mesmos tanto no Facebook quanto no Instagram, mas a análise dos dados respeitou as especificidades de cada uma das redes sociais, além de observar a linguagem empregada e ter como base a LAI. Nas mídias sociais, com a análise de conteúdo, para além do título da postagem e da data de publicação, foram estabelecidas as seguintes categorias de análise:

Quadro 1 - Critérios de categorização - finalidade

\begin{tabular}{cc}
\hline Categorias & Finalidade \\
\hline Tema & Observar quais os temas mais recorrentes nas postagens \\
Interação & Entender como o público reage aos conteúdos publicados \\
Linguagem & $\begin{array}{c}\text { Analisar se a comunicação é feita de forma acessível e de fácil } \\
\text { entendimento do público }\end{array}$ \\
Material complementar (MC) & $\begin{array}{c}\text { Observar se o conteúdo publicado oferece algum material extra que } \\
\text { ajude no aprofundamento do assunto, já que as mídias sociais são de } \\
\text { conteúdos e leituras rápidas } \\
\text { Peça gráfica (PG) }\end{array}$ \\
Saber qual material gráfico é usado para complementar a \\
comunicação
\end{tabular}

A partir das categorias foi possível saber quais os temas discutidos durante o período de coleta, a interação entre a instituição e o público e, ainda, se a comunicação foi efetiva. Isso porque estar presente nas mídias sociais e postar notícias não é suficiente para garantir a qualidade da comunicação. Outro ponto analisado foi a utilização de peças gráficas para captar mais a atenção 
de quem está passando pelo feed. Com o grande número de publicações, é importante que a parte gráfica seja usada com sabedoria, explorando os recursos de fotos, criação de artes, animações e carrossel de imagem, como no caso do Instagram.

A metodologia utilizada, para além do uso das ferramentas acima citadas, foi a análise de conteúdo sob ótica de conceitos como a comunicação pública, lei de acesso à informação e o trabalho da assessoria de imprensa. Para observar a CP foram consideradas os quatro eixos centrais que indicam pré-requisitos para a ação dos agentes e instituições que lidam com a comunicação de interesse público: transparência, acesso, interação e a ouvidoria social. Também foram observados o interesse público, a divulgação de atos institucionais e matérias legislativas, o diálogo, participação e possibilidade de interatividade/contato e a transparência. Posto isso, a análise de conteúdo baseou-se na Assessoria de Imprensa, Lei de Acesso à Informação e Comunicação Pública com as seguintes subcategorias:

Quadro 2 - Critérios de categorização e subcategorias

\begin{tabular}{|c|c|c|c|}
\hline Categorias & \multicolumn{3}{|c|}{ Subcategorias } \\
\hline Assessoria de Imprensa (AI) & $\begin{array}{c}\text { Divulgação de notícia ou trabalho } \\
\text { institucional (DN) }\end{array}$ & Facilit & $\begin{array}{l}\text { prestação de informação } \\
\text { (FP) }\end{array}$ \\
\hline $\begin{array}{l}\text { Lei de Acesso à Informação } \\
\text { (LAI) }\end{array}$ & Transparência e Publicidade (TP) & Lib & ade de Expressão (LE) \\
\hline Comunicação Pública (CP) & Interesse Público (IP) & go (D) & $\begin{array}{c}\text { Tornar conhecidos os } \\
\text { trabalhos da instituição } \\
\text { (TC) }\end{array}$ \\
\hline
\end{tabular}

Fonte: Elaborado pelas autoras com base na pesquisa bibliográfica, 2021.

Já para o site institucional foi proposta uma análise partindo da LAI, conforme critérios com os quais foi possível saber se a CMU segue a legislação e trabalha a transparência ativa e passiva, em especial ao que se refere ao e-Sic. Foram observados os canais de comunicação disponíveis, a facilidade de acesso às informações de interesse público e o respeito à Lei de Acesso à Informação, com base nos critérios descritos por Valdiones et al. (2019).

\subsection{Contexto de pré-análise}

Durante o monitoramento foi necessário considerar dois fatores que permeiam o contexto de análise do objeto em questão. A primeira, de viés político, diz respeito à prisão de 20 dos 27 vereadores em dezembro de 2019. Os parlamentares foram alvo de uma operação coordenada pelo MP para investigar desvio de dinheiro público, ações nas quais as verbas de gabinete foram usadas para contratar irregularmente empresas de segurança, limpeza e gráfica. Embora não tenha acontecido durante o período de monitoramento, as mídias sociais e site, até o mês de maio, 
discutiram muito sobre o assunto. Isso porque, com a prisão, houve remanejamento das vagas do legislativo. Convocação de suplentes, posses, processos de cassação, renúncias e até mesmo retomada ao exercício por um deles, que recorreu em instâncias superiores. Grande parte das publicações coletadas, inclusive, dizem respeito a esses processos.

Além disso, em março de 2020, a pandemia de Covid-19 chegou ao Brasil. Uberlândia teve seu primeiro caso em 17 de março e o primeiro óbito confirmado em 2 de abril. Dias depois do caso número 1, a Prefeitura decidiu pelo fechamento do comércio local como uma das medidas de contenção do contágio da doença. Ademais, a ideia era de que o período do monitoramento terminasse quando teria início o período eleitoral e quando, geralmente, os perfis em mídias sociais são desativados até que as eleições terminem. No entanto, no final do mês de junho de 2020 decidiu-se que as eleições seriam adiadas para novembro por razões de segurança sanitária em decorrência da pandemia.

Nesse contexto, em meados de 2020, a Câmara não apenas estava com a credibilidade abalada pelo caso de desvio de dinheiro como também porque a cidade toda enfrentava os problemas decorrentes da pandemia de coronavírus. É, portanto, um período no qual os vereadores precisariam não apenas estar cada vez mais preocupados com a transparência para melhorar a imagem do Legislativo, mas também focados em propor ações que auxiliassem Uberlândia a passar por este período. A solução deveria vir com medidas de fiscalização mais severas para evitar o uso indevido do dinheiro público e ao fim ao qual é destinado, projetos que diminuíssem os impactos econômicos e sociais na cidade e, ainda, atenção ao acesso à informação em um período em que as pessoas ficaram mais conectadas e os serviços e atendimento na Câmara passaram a não serem presenciais, com reuniões realizadas de forma remota e escalonamento das atividades.

A partir da análise de conteúdo foi possível observar que houve 63 postagens no Facebook e 51 no Instagram, sendo as duas redes vinculadas e compartilhando os mesmos conteúdos, sem adaptação ou com poucas alterações. Uma vez que os conteúdos são os mesmos, consideramos o Facebook para chegar à conclusão de que o tema "Cassação" foi o mais recorrente, aparecendo em 24 postagens. A lista segue da seguinte forma: "Leis" dez vezes; "Reuniões" e "CPI" seis vezes cada uma; "Funcionamento da Câmara" quatro vezes; e "Pandemia" e "Eleições" três vezes cada uma. Há ainda outros oito assuntos citados menos de três a uma vez. Se somados, os números são maiores que o total de postagens, uma vez que algumas postagens abrangem mais de um tema. Em nenhuma das duas mídias houve alguma postagem sem interação. Por interação entende-se curtidas, reações, comentários e compartilhamentos.

No quesito linguagem, $73 \%$ das publicações obedeceram a critérios como linguagem simples e clara. Para o Facebook foi desconsiderada a ideia de que um texto longo seria um problema, visto que, como descrito acima, é uma mídia que comporta textos maiores e que há a 
possibilidade de lê-los na versão desktop, ao contrário do Instagram (mídia focada em imagens, instantaneidade e que é mais acessada por meio de aplicativo de celular). Os textos longos foram considerados problemáticos apenas se usados no Instagram, pois no Facebook os problemas se relacionavam à construção textual propriamente dita. Como exemplo pode-se citar o texto publicado em 06 de abril, acerca de audiência para tratar da cassação dos vereadores envolvidos nos escândalos, e que apresenta equívocos na construção do texto e na citação da legislação.

1 - Linguagem utilizada na página do Facebook

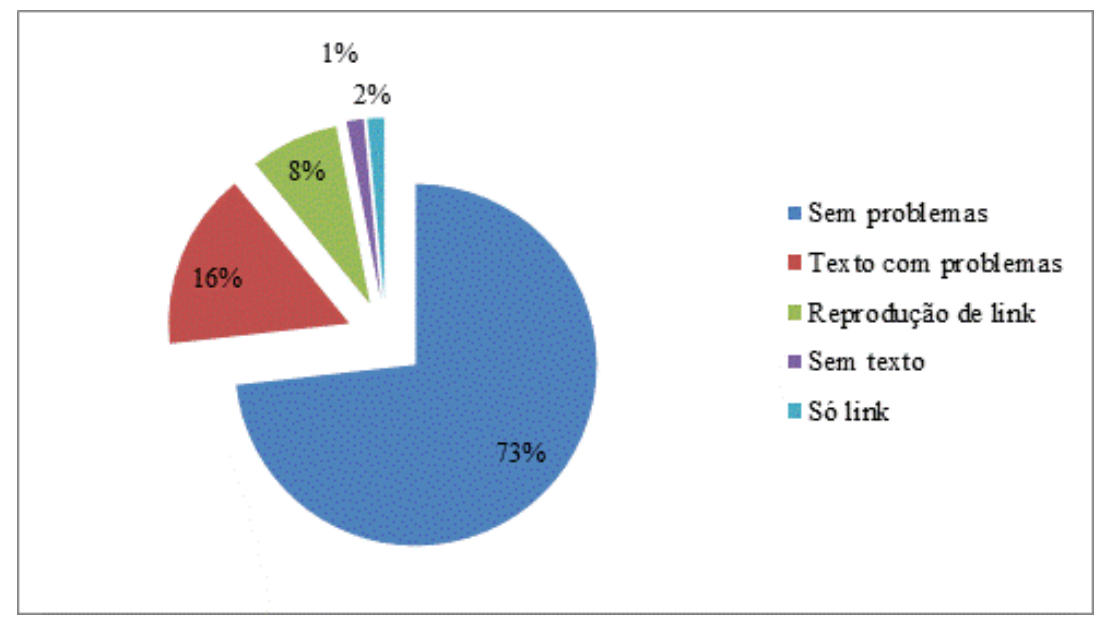

Fonte: Elaborado pelas autoras, 2021.

No entanto, $16 \%$ é um número significativo quando se pensa na quantidade de pessoas que podem ter tido problemas para interpretar ou entender tais textos. Isso porque o profissional de assessoria de imprensa deve atuar como facilitador, no qual seu papel fundamental é colaborar, fornecendo informações necessárias, das mais básicas às mais elaboradas (TAVARES, 2016).

Nesse ponto, a reprodução do conteúdo no Instagram diverge um pouco. A maioria dos textos lá publicados é curta e, talvez por isso, percam os problemas presentes na outra mídia social analisada. Alguns deles são publicados apenas o primeiro parágrafo original e um link para acessar a matéria completa no site.

Este, por consequência, é outro problema. A ideia de compartilhar um link externo e que leve para um material mais elaborado para quem tem interesse em uma leitura mais densa é ótima, mas só funciona para o Facebook, que permite o redirecionamento. No Instagram, o que era para ser um link fica como um texto normal e, mesmo usando um encurtador de URL, ainda é pouco provável que a pessoa vá decorá-lo ou copiá-lo e editá-lo no navegador do celular para ter acesso à matéria na íntegra.

Para além disso, as peças dos posts se resumem a fotos, correspondendo a 53 das 63 postagens do Facebook, principalmente da mesa diretora nas sessões durante os trabalhos legislativos. Embora o ambiente seja sempre o mesmo, é possível trazer outras versões e elementos, de acordo com o tema abordado, como artes, mais vídeos e, no caso do Instagram, 
Transparência e interesse público: o trabalho de acesso à informação e comunicação pública na Câmara Municipal de Uberlândia -MG

uma arte desdobrada em um carrossel de imagens. Todos os recursos das mídias não só podem como devem ser explorados para reter a atenção do usuário da rede que vive rolando o feed.

Partindo para a análise sobre o trabalho da assessoria de imprensa, foram propostas duas subcategorias: Divulgação de notícia ou trabalho institucional (DN) e Facilitar a prestação de informação (FP). Para considerar que a CMU faz assessoria de imprensa, os dois critérios deveriam ser atendidos. Dessa forma, a partir da análise de conteúdo no Facebook, 85,7\% das publicações atendem aos dois principais critérios propostos.

A categoria seguinte diz respeito ao atendimento à LAI. Para tanto, duas categorias foram propostas: Transparência e Publicidade (TP) e Liberdade de Expressão (LE). Nesse caso, a transparência e publicidade dizem respeito à prestação de contas por meio dos canais digitais e à promoção da CMU e a Liberdade de Expressão considera a possibilidade de interagir com as postagens e outros usuários, bem como expressar livremente. Para esta última, os comentários que foram considerados como forma de liberdade de expressão e não as interações prontas, como curtidas e reações. Os dois primeiros conceitos não foram separados porque, apesar de diferentes, foi considerado que na maioria das publicações, principalmente sobre a cassação dos vereadores afastados, a instituição se promove por meio dessa transparência e da possibilidade de a população saber de todos os passos dados pelas comissões processantes. Dessa forma, 55,5\% atendem aos critérios propostos da LAI no Facebook.

Por fim, a análise observou a Comunicação Pública considerando três subcategorias: Interesse Público (IP), Diálogo (D) e Tornar conhecidos os trabalhos da instituição (TC). A primeira segue toda a conceituação proposta até aqui. A segunda, por sua vez, leva em consideração se nas postagens existe interação entre os usuários, sejam entre eles mesmos ou com a instituição. Por fim, a última subcategoria considera todo e qualquer trabalho feito pela CMU e seus vereadores. Dessa forma, o órgão atende apenas a 19,04\% de todos os pontos observados no Facebook e que estavam diretamente relacionados com a CP. Este ponto dialoga com Duarte (2009), quando ele aponta que a Comunicação Pública está baseada principalmente no interesse público e no diálogo com a população, o que não foi efetivamente atingido aqui.

Quanto à LAI e à CP, o Instagram diverge do Facebook a partir do momento em que a interação é menor e, em nenhuma publicação, o perfil se manifestou para tirar alguma dúvida dos usuários da rede, como faz em algumas postagens do Facebook. Dessa forma, considerando a mesma forma de avaliação e, tendo em vista que a quantidade de postagens foi menor, os resultados foram: AI 96,07\%, LAI 37,25\% e CP 0\%. Os resultados aqui apresentados, principalmente em relação à $\mathrm{CP}$ e aos critérios estabelecidos para realizá-la, sinalizam pequenas diferenças nos critérios utilizados, principalmente no que diz respeito a como identificar a $\mathrm{CP}$ utilizadas por Koçouski (2013) e Duarte (2009). Já Matos (2013) corrobora a proposta de Duarte (2009) quando aponta que a Comunicação Pública deve ser pensada como um processo político que pretende integrar a expressão, a interpretação e o diálogo entre o cidadão e o Estado. 
Quem trabalha com mídias sociais tem à disposição uma série de ferramentas para acompanhar os dados das páginas que gerencia. São a partir desses dados e métricas que é possível melhorar o desempenho das redes. Para analisar dados da página no Facebook foi utilizada a Fanpage Karma. A partir dela foi notou-se que, nesse período, a publicação com maior interação $(1,7 \%)$, com 33 likes e nove comentários, nem foi relacionada a assuntos da Câmara, mas sim uma nota de pesar pelo falecimento de um ex-prefeito da cidade. Em seguida, vem a aprovação da lei que torna obrigatório o uso de máscara como forma de proteção à Covid-19, publicado em 17 de abril de 2020 e que obteve 18 likes e 15 comentários (1,1\% de interação e $5^{\text {a }}$ com maior número de likes).

Outro dado observado foi o uso de palavras e hashtags. Nota-se que não há quase nenhuma frequência e baixo engajamento dos termos usados. $\mathrm{O}$ uso das hashtags nas mídias sociais pode expandir o alcance da marca, promovendo um envolvimento maior entre os usuários da rede. Mesmo assim, o número de curtidas na página aumentou de 3.711 para 3.846 no citado período. Analisando como um todo, nesses três meses a fanpage teve uma interação média de $0,4 \%$ e um engajamento de $0,28 \%$.

Passando para os dados do Instagram, analisados conforme a ferramenta Hype Auditor, o percentual de pessoas engajadas com o conteúdo chega a apenas $0,92 \%$, sendo que dos 1.900 seguidores da época 703 eram considerados uma "audiência de qualidade" e apenas 6 pessoas eram realmente engajadas. No entanto, é preciso abrir um parêntese que, nas postagens analisadas, pode-se notar que dois deles são um vereador e um servidor. Ainda sobre a audiência foi mostrado que a interação é baixa, levando em consideração tanto as curtidas quanto os comentários, como foi observado na análise de conteúdo.

Os seguidores, por sua vez, correspondem a 73\% da cidade de Uberlândia e são definidos pela ferramenta da seguinte forma: $37,5 \%$ de pessoas reais, $0,4 \%$ de influenciadores (conta com mais de cinco mil seguidores), 40,6\% de massfollowers (contas com mais 1500 seguidores e que usam ferramentas automáticas de ganhar seguidores) e 21,5\% de contas suspeitas (robôs ou pessoas que usam serviços específicos para likes, comentários e seguidores), conforme definições da própria plataforma de análise.

Pode-se concluir que a equipe responsável precisa se aprofundar nos conhecimentos teóricos discutidos ao longo desta pesquisa para focar em um plano de comunicação efetivo e que contemple o interesse público, a transparência, a publicidade e, ainda, atuar como mediadores da informação. Não foi observada nenhuma publicação no período analisado, entre os meses de abril e junho de 2020, em que a interação e o diálogo com a comunidade foram priorizados ou incentivados.

Dessa forma, esse resultado, juntamente com os demais coletados até aqui sobre as fanpages, vai contra o que aponta Duarte (2009) quando menciona que a Comunicação Pública exige: privilegiar o interesse público; centralizar o processo no cidadão; tratar a comunicação 
como um processo dialógico; adaptar instrumentos às necessidades, possibilidades e interesses públicos.

Nas mídias sociais conclui-se que a questão da transparência e, principalmente, da comunicação pública precisa ser repensada e melhor trabalhada, assim como os estudos das mídias sociais, para definir as especificidades de cada uma e o potencial que elas permitem trabalhar um tema tão relevante quanto política.

A análise do site institucional foi feita à luz da LAI e levando em conta o e-Sic. No decorrer da análise foram encontrados problemas no sistema que impossibilitaram a análise completa.

A LAI prevê que, para a transparência ativa, a legislação precisa de fácil acesso e, ainda, que devem ser disponibilizados tutoriais de como usar o sistema eletrônico e que os relatórios de todos os pedidos de informação devem ser públicos. Dessa forma, a Câmara atende apenas a 50\% dos critérios estipulados. Aqui, cabe relembrar o que foi apresentado no capítulo 3, que devem estar disponíveis os números sobre os pedidos e os recursos, com estatísticas extraídas diariamente do e-SIC. Tais dados podem ser apenas consultados ou o cidadão pode fazer o download dos relatórios.

No entanto, o problema maior encontra-se na transparência passiva. É previsto que o pedido de informação possa ser feito tanto com cadastro como de forma anônima. Contudo, a plataforma não permitiu que a solicitação fosse feita de nenhuma das duas formas. Para informações anônimas, a seguinte mensagem era exibida, depois de preencher todos os campos: "Não é possível criar o processo. Usuário padrão não identificado!".

Em uma segunda tentativa, fazendo o cadastro e preenchendo as informações básicas, é informado que a validação será enviada por e-mail, mas esta confirmação nunca chegou. Posteriormente, tentou-se cadastrar outro endereço, mas só é possível fazer um cadastro com os dados, especialmente porque pedem CPF. A mensagem foi a seguinte: "Erro ao salvar o usuário. Já existe um usuário para uma pessoa com os dados informados. Entre em contato com o setor de cadastro". Solicitou-se que outras pessoas fizessem o procedimento e o resultado foi o mesmo.

Outra inconsistência é que o site informa que, havendo erro, o setor de cadastro deve ser procurado. No entanto, não existem informações sobre como entrar em contato com o setor nem de forma online quanto presencial. Mesmo se desconsiderássemos a pandemia, é previsto na legislação que os pedidos sejam feitos por meios eletrônicos para dar mais transparência aos atos. Além disso, serve para facilitar o processo de pedido de informação àqueles que não têm tempo de comparecer à Câmara, visto que a instituição funciona em horário comercial, quando o cidadão está trabalhando.

Posto isso, a Câmara de Uberlândia atende a apenas 9,09\% dos critérios analisados em relação à transparência passiva e que diz respeito a três pontos principais: receber o pedido de acesso; registrar este pedido, bem como entregar o número de protocolo, com data; e, por fim, 
encaminhar o pedido do cidadão ao setor competente que fornecerá a informação solicitada. $\mathrm{O}$ resultado dialoga com os estudos de Valdiones et. al. (2019), realizado em todo o país, que mostra as dificuldades para realizar, acompanhar e consultar os pedidos de informação, muitas vezes até impedindo que o usuário faça alguma solicitação a partir do sistema.

Concluiu-se que, no site, o acesso à informação é precário, visto que até a conclusão desta pesquisa não era possível realizar cadastro e solicitações por meio do e-Sic, o que é cabível de penalidades. A CMU foge, portanto, do que é estabelecido na legislação, uma vez que o sistema para pedido de informações não atinge seus pontos principais: receber o pedido de acesso; registrar este pedido, bem como entregar o número de protocolo, com data; e, por fim, encaminhar o pedido do cidadão ao setor competente que fornecerá a informação solicitada. (BRASIL, 2012). Se o cidadão não chega sequer à primeira parte, torna-se até irrelevante citar aqui o cumprimento dos prazos.

Vale reforçar que, no cenário atual de pandemia e distanciamento social, os processos deveriam estar cada vez mais focados no online, não apenas para garantir o direito do cidadão ao acesso à informação, mas também a segurança sanitária para evitar que os solicitantes precisem se deslocar para fazer o pedido. A Câmara de Uberlândia passou por uma situação delicada de prisão e cassação da maioria dos vereadores, afetando negativamente a imagem da instituição. Investir na transparência e facilitar o que já é previsto na LAI não apenas é obrigatório, mas ajudaria na retomada da credibilidade do órgão e seus agentes.

\section{Considerações Finais}

A pesquisa acompanhou e analisou as mídias sociais Facebook e Instagram e o site institucional da Câmara Municipal de Uberlândia por três meses, entre abril e junho de 2020, com o objetivo de averiguar como são tratadas e divulgadas as questões de interesse público nos canais oficiais de comunicação, ponderando os conteúdos das matérias legislativas, mensuração da resposta dos usuários às postagens nas mídias e demais questões.

Com base na pesquisa bibliográfica e nos dados apresentados, podemos concluir que ainda há um processo de melhoria pelo qual a assessoria da Câmara de Uberlândia precisa passar. Conhecer o conceito de comunicação pública e accountability são alguns dos passos iniciais. É preciso entender que, hoje, a quantidade de pessoas que se informam por meio das mídias sociais, principalmente o Facebook, é significativa. Os canais digitais são potenciais que devem ser trabalhados, não só para que a informação chegue ao maior número possível de pessoas, mas fazendo isso de uma forma em que os assessores de imprensa trabalhem como facilitadores do conhecimento, tornando a linguagem clara e não deixando que os termos técnicos sejam um fator excludente para o exercício da cidadania. Para além disso, é preciso entender as especificidades das mídias e usá-las a favor da população, principalmente estreitando laços e promovendo o diálogo, que é sim possível mesmo no online. 
Por fim, o site institucional apresenta grandes problemas quanto ao acesso e impossibilita o pedido de informação, seja ele por meio de cadastro ou de forma anônima, como previsto por lei. Relatórios também não são apresentados, o que descaracteriza o princípio da transparência.

Respondendo à inquietação inicial sobre transparência e o interesse público, pode-se concluir que, a partir do material e período analisados, a Câmara Municipal de Uberlândia não realiza comunicação pública nas mídias sociais, uma vez que a maioria dos assuntos inerentes à coletividade não são sequer divulgados amplamente. Outro ponto é que não há respeito à Lei de Acesso à Informação no que tange os pedidos realizados de forma online pelo e-Sic, conforme legislação aprovada e que pode acarretar penalidades caso alguém registre denúncia.

\section{Referências}

AMORIM, M. R. L.; SILVA, F. S. Impactos da Implantação da Lei de Acesso à Informação no Serviço Público: uma Análise das Dificuldades e Benefícios à Cidadania. SEGeT 2014 - XI Simpósio de Excelência em Gestão e Tecnologia. Não publicado. Disponível em: http://www.aedb.br/seget/arquivos/artigos14/8820506.pdf. Acesso em: 12 abr. 2020.

BATISTA, M. A difusão da Lei de Acesso à Informação nos municípios brasileiros: fatores internos e externos. Brasília: Enap, 2017. 84 p. Disponível em: https://repositorio.enap.gov.br/bitstream/1/3125/1/Cadernos_53.pdf. Acesso em: 14 abr. 2020.

BRANDÃO, E. P. Usos e Significados do Conceito Comunicação Pública. In: Congresso Brasileiro de Ciências da Comunicação, 29, 2006, Brasília. Anais.... São Paulo: Intercom, 2006. Disponível em: http://www.portcom.intercom.org.br/pdfs/38942022201012711408495905478367291786.pdf. Acesso em: 20 abr. 2020.

BRASIL. Constituição da República Federativa do Brasil. Brasília, DF: Senado Federal, 1988.

BRASIL. Decreto lei $\mathrm{n}^{\circ}$ 7.724, de 16 de maio de 2012. Regulamenta a Lei no 12.527, de 18 de novembro de 2011, que dispõe sobre o acesso a informações previsto no inciso XXXIII do caput do art. 5o, no inciso II do § 30 do art. 37 e no $§ 20$ do art. 216 da Constituição. Diário Oficial União, Brasília, DF, 16 mai. 2012. Seção 1,p. 1. Retificação. Diário Oficial da União Seção 1 - 18/5/2012, Página 3. Disponível em http://www.planalto.gov.br/ccivil_03/_ato20112014/2012/decreto/d7724.htm. Acesso em: 16 out. 2019.

CAMPOS, A. M.. Accountability: quando poderemos traduzi-la para o português?.Revista de Administração Pública, Rio de Janeiro, v. 24, n. 2, p. 30 a 50, jun. 1990. ISSN 1982-3134. Disponível em: http://bibliotecadigital.fgv.br/ojs/index.php/rap/article/view/9049. Acesso em: 09 Jun. 2020.

CUNHA, M.A. et al. Transparência governamental eletrônica para Accountability. In: PINHO, J.A.G. (ed.) Artefatos digitais para mobilização da sociedade civil: perspectivas para avanço da democracia [online]. Salvador: EDUFBA, 2016, pp. 119-139. ISBN: 978-85-232-1877-5.

Disponível em: http://books.scielo.org/id/hk62f/pdf/pinho-9788523218775-07.pdf. Acesso em: 15 abr. 2020.

DINES, A. Introdução: Assessorias (e/ou/versus) Imprensa. In: DUARTE, J (org.). Assessoria de Imprensa e relacionamento com a mídia. $2^{\text {a }}$ edição. São Paulo: Atlas, 2009.

DUARTE, J. Assessoria de Imprensa no Brasil. In: DUARTE, J (org.). Assessoria de Imprensa

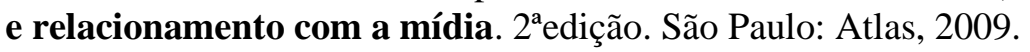

FLORES, C. M. Comunicação pública e assessoria de imprensa: apontamentos acerca da 
Fundação de Economia e Estatística Siegfried Emanuel Heuser do estado do Rio Grande do Sul. 2016. 83 p. Trabalho de Conclusão de Curso (Graduação em Relações Públicas) Universidade Federal de Santa Maria, Santa Maria, RS, 2016.

HASWANI, M. O discurso obscuro das leis. In: MATOS, H. (Org.) Comunicação pública: interlocuções, interlocutores e perspectivas. São Paulo: ECA/USP, 2013, p. 71-96. Disponível em: http://www3.eca.usp.br/sites/default/files/form/ata/pos/quarto.pdf. Acesso em: 21 abr. 2020.

KOÇOUSKI, M. Comunicação Pública: construindo um conceito. In: MATOS, H. (Org.) Comunicação pública: interlocuções, interlocutores e perspectivas. São Paulo: ECA/USP, 2013, p. 71-96. Disponível em:

http://www3.eca.usp.br/sites/default/files/form/ata/pos/quarto.pdf. Acesso em: 20 abr. 2020.

KUNSCH, M. M. K. Comunicação pública: direitos de cidadania, fundamentos e práticas. In:

MATOS, H. (Org.) Comunicação pública: interlocuções, interlocutores e perspectivas. São Paulo: ECA/USP, 2013, p. 13-30. Disponível em:

http://www3.eca.usp.br/sites/default/files/form/ata/pos/quarto.pdf. Acesso em: 20 abr. 2020.

RIBEIRO, E. M. A. O.; MAINIERI, T..A comunicação pública como processo para o exercício da cidadania: o papel das mídias sociais na sociedade democrática. Organicom, v. 8, n. 14, p. 49-61, jun. 2011.

ROCHA, A. C. A accountability na administração pública: modelos teóricos e abordagens.

Contabilidade, Gestão e Governança, v. 14, n. 2, p. 82-97, set. 2011.

SARDINHA, A. C. Questões teóricas sobre a Comunicação Pública e deliberação na democracia participativa brasileira - um estudo de caso. Biblioteca On-line de Ciências da Comunicação, v. 1, p. 01-60, 2012. Disponível em: http://www.bocc.ubi.pt/pag/sardinhaantonio-questoes-teoricas-sobre-a-comunicacao-politica.pdf. Acesso em: 20 abr. 2020.

TAVARES, A. F. Comunicação pública e acesso à informação: o interesse público presente nas produções da assessoria de imprensa da Prefeitura de Santarém (PA). 2016. Dissertação (Mestrado em Tecnologias, Comunicação e Educação). Universidade Federal de Uberlândia, 2016.

VALDIONES, A. P. et al. Panorama dos sistemas eletrônicos de informação ao cidadão: uma análise das ferramentas de diferentes órgãos públicos. São Paulo: Artigo 19, 2019.

Disponível em: https://artigo19.org/wp-

content/blogs.dir/24/files/2019/05/A19_ESICS_web_2019.pdf. Acesso em: 14 abr. 2020.

WE ARE SOCIAL. Digital in 2020. 2020. Relatório acerca da comunicação digital relativo ao ano de 2020. Disponível em: https://datareportal.com/reports/digital-2020-brazil. Acesso em: 25 ago. 2020.

Artigo submetido em: 2021-03-23

Artigo reapresentado em: 2021-04-26

Artigo aceito em: 2021-05-06 